\title{
A Novel Hysteresis Control Strategy Based on Ampere-Second Balance of the Modulate Capacitor
}

\author{
Jin-Bin $\mathrm{Zhao}^{\dagger}$, Jian-Feng Dai ${ }^{*}, \mathrm{Ke}-\mathrm{Qing} \mathrm{Qu}^{*}$, and Fen $\mathrm{Li}^{*}$ \\ $\dagger^{*}$ College of Electrical Engineering, Shanghai University of Electric Power, Shanghai, China
}

\begin{abstract}
A novel hysteresis PWM control strategy for synchronous buck converter is proposed. The proposed control strategy is based on ampere-second balance of the modulate capacitor, which not only offers faster transient response to meet the challenges of the power supply requirements of fast dynamic load changes, but also provides better stability and solves the compensation problem of error amplifier in the conversional voltage PWM control. Finally, the steady-state and dynamic operation of the control method is analyzed and verified by simulation and experimental results.
\end{abstract}

Keywords: Ampere-second, Buck converter, Fast transient response, Hysteresis control

\section{INTRODUCTION}

Nowadays, DC-DC switching converters have been increasingly used in a wide range of applications, such as LEDs, air-space industry, portable systems, and power factor correction [1]-[6]. The requirements of the transient response performance of the DC-DC power switching converters are stringent. This performance is consistently expected to have a lower dynamic output voltage deviation and shorter settling time during load current transients. As one of the widely used converter topologies, buck converters have been investigated with different control strategies [7]-[18]. Voltage mode converter is a traditional PWM control buck converter that operates in continuous conduction mode (CCM), which requires a complicated compensation network to ensure stable operation challenged by complex poles in the loop gain transfer function [7]. This challenge not only increases the design difficulty of the control circuit, but also causes poor dynamic load performance. Many investigations have been carried out on this subject to avoid these difficulties. The current mode control is applied with voltage feedback to improve stability and dynamic performance [8], [9], which needs complex slope compensation and response speed limited by voltage loop controller. In [10]-[12], time-optimal digital and digital controllers are presented. These techniques significantly

Manuscript received May 10, 2014; accepted Jul. 7, 2014

Recommended for publication by Associate Editor Se-Kyo Chung.

${ }^{\dagger}$ Corresponding author: zhaojinbin@shiep.edu.cn

Tel: + 86-21-35305346, Shanghai University of Electric Power

${ }^{*}$ College of Electrical Eng., Shanghai University of Electric Power, China improve transient response, but suffer from complex implementation. In [13]-[15], nonlinear sliding-mode are presented to improve the dynamic response. However, the main drawback of sliding mode is variable frequency. Control strategies such as hysteresis control have received extensive attention. These strategies do not need compensation circuit and provide almost instantaneous load transient response [16]-[18].

A novel hysteresis PWM control strategy based on ampere-second balance of the modulate capacitor is proposed. The proposed control strategy imports the inductor current information in the feedback loop of single output voltage as well as adds inductor current and output voltage as feedback variables. These variables improve capacitor charging and discharging rates effectively. Moreover, only a comparator is used with hysteresis, feedback resistors, and current sensor. Hence, the number of components will be obviously reduced in the control circuit. No error amplifier and complex compensating network is found. Hence, faster response was achieved when the load suddenly changes.

The operating principles of the proposed control strategy are introduced in Section II. The steady-state was analyzed. A small-signal model is derived and analyzed to show the advantages of the proposed control strategy in Section III. The prototype board is tested. The simulation and experimental results are verified in Section IV. The conclusion is given in Section $\mathrm{V}$.

\section{OPERATING PRINCIPLES}




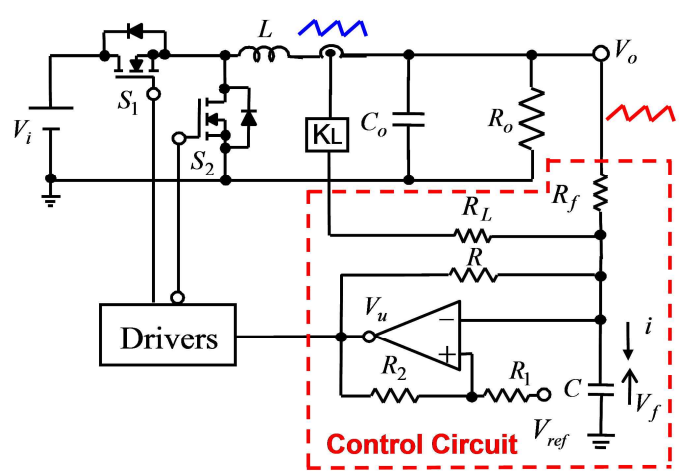

Fig. 1. Circuit diagram of the proposed converter.

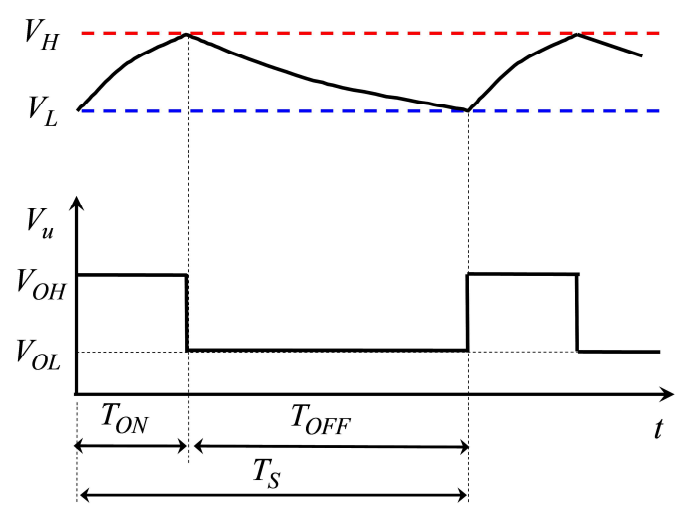

Fig. 2. Key waveforms of the comparator.

The configuration of a buck converter with a synchronous rectifier that uses the proposed control strategy is shown in Fig. 1. The key waveforms of comparator $U$ in one switching cycle are shown in Fig. 2. The control circuit consists of a comparator $U$ with hysteresis and feedback resistors $R_{f}$ and $R_{L}$. The output voltage and inductor current are returned to capacitor $C$ for the triangular wave generator through resistor $R_{f}$ and $R_{L}$, respectively. In addition, the output of the hysteresis comparator was connected with the noninverting input terminal through resistor $R_{2}$ and then connected with $V_{\text {ref }}$ through resistor $R_{l}$. Therefore, the upper and lower thresholds of hysteresis controlled buck converter were obtained when the output of comparator $U$ changed.

The working principle of the control circuit is as follows: When the output voltage becomes large (small), the charging current of capacitor $C$ in the on mode period increases (decreases), and the discharging current of capacitor $C$ in the off mode period decreases (increases). Hence, the on time duration of the pulse decreases (increases) and off time duration increases (decreases). Therefore, the switching duty was changed. Moreover, the output voltage can be regulated.

\section{OPERATION ANALYSIS}

\section{A. Steady-State Analysis}

To simplify the analysis, all circuit elements are assumed to be ideal. In Fig. $1, V_{f}$ is the voltage across capacitor $C . V_{L}$ and
$V_{H}$ are the threshold levels of comparator $U . V_{U}$ is the output voltage of comparator $U$. The switching cycle starts at instant $\mathrm{t}=0$.

(i) state 1: $0<t<T_{O N}$

When the output signal $V_{U}$ is at a high level, the capacitor was charged through the feedback branch. The following equations are obtained:

$$
i=C \frac{d V_{f}}{d t}=\frac{V_{O H}-V_{f}}{R}+\frac{V_{o}-V_{f}}{R_{f}}+\frac{V_{i L}-V_{f}}{R_{L}}
$$

Solving the above equations under the initial condition of $V_{f}$ $(0)=V_{L}$ obtains the next equation as follows:

$$
V_{f}=V_{L} e^{\frac{-1}{R_{p} C} t}+\frac{V_{O H} R_{p}}{R}\left(1-e^{\frac{-1}{R_{p} C} t}\right)+\frac{V_{o} R_{p}}{R_{f}}\left(1-e^{\frac{-1}{R_{p} C} t}\right)+\frac{V_{i L} R_{p}}{R_{L}}\left(1-e^{\frac{-1}{R_{p} C} t}\right)
$$

$$
\text { where } \frac{1}{R_{p}}=\frac{1}{R}+\frac{1}{R_{f}}+\frac{1}{R_{L}}
$$

From Equation (2), $V_{f}$ increases exponentially from $V_{L}$ to $\frac{R_{p}}{R} V_{O H}+\frac{R_{p}}{R_{f}} V_{o}+\frac{R_{p}}{R_{L}} V_{i L}$. Since $V_{f}$ must be greater than $V_{H}$ to invert the state of the comparator, the next constraint is obtained as follows:

$$
\frac{R_{p}}{R} V_{O H}+\frac{R_{p}}{R_{f}} V_{o}+\frac{R_{p}}{R_{L}} V_{i L}>V_{H}
$$

Setting $V_{f}=V_{H}$ and $t=T_{O N}$ in Equation (2) obtains $T_{O N}$ as follows:

$$
T_{O N}=C R_{p} \ln \frac{\frac{R_{p}}{R} V_{O H}+\frac{R_{p}}{R_{f}} V_{o}+\frac{R_{p}}{R_{L}} V_{i L}-V_{L}}{\frac{R_{p}}{R} V_{O H}+\frac{R_{p}}{R_{f}} V_{o}+\frac{R_{p}}{R_{L}} V_{i L}-V_{H}}
$$

If $V_{H}-V_{L}<<\frac{R_{p}}{R} V_{O H}+\frac{R_{p}}{R_{f}} V_{0}+\frac{R_{p}}{R_{L}} V_{i L}-V_{H}$, the Equation

(4) can be approximated as follows:

$$
T_{O N} \approx C R_{p} \frac{V_{H}-V_{L}}{\frac{R_{p}}{R} V_{O H}+\frac{R_{p}}{R_{f}} V_{o}+\frac{R_{p}}{R_{L}} V_{i L}-V_{H}}
$$

(ii) state 2: $T_{O N}<t<T_{s}$

When output signal $V_{U}$ is at a low level, the capacitor was discharged through the feedback branch. The following equations are obtained:

$$
i=C \frac{d V_{f}}{d t}=\frac{-V_{f}}{R}+\frac{V_{o}-V_{f}}{R_{f}}+\frac{V_{i L}-V_{f}}{R_{L}}
$$

Solving the above equations under the initial condition of $V_{f}\left(T_{O N}\right)=V_{H}$ obtains the next equation as follows:

$$
V_{f}=\left(\frac{R_{p}}{R_{f}} V_{o}+\frac{R_{p}}{R_{L}} V_{i L}\right)+\left[V_{H}-\left(\frac{R_{p}}{R_{f}} V_{o}+\frac{R_{p}}{R_{L}} V_{i L}\right)\right] e^{\frac{-1}{R_{p} C}\left(t-T_{O N}\right)}
$$

From Eq. (7), $V_{f}$ decreases exponentially from $\mathrm{V}_{\mathrm{H}}$ to $\frac{R_{p}}{R_{f}} V_{o}+\frac{R_{p}}{R_{L}} V_{i L}$. Since $V_{f}$ must be lower than $V_{L}$ to invert the 
state of the comparator, the next constraint is obtained as follows:

$$
\frac{R_{p}}{R_{f}} V_{o}+\frac{R_{p}}{R_{L}} V_{i L}<V_{L}
$$

From Equation (7), $T_{O F F}$ is obtained by setting $V_{f}=V_{L}$ and $t=$ $T_{S}$ as follows:

$$
T_{\text {OFF }}=C R_{p} \ln \frac{V_{H}-\left(\frac{R_{p}}{R_{f}} V_{o}+\frac{R_{p}}{R_{L}} V_{i L}\right)}{V_{L}-\left(\frac{R_{p}}{R_{f}} V_{o}+\frac{R_{p}}{R_{L}} V_{i L}\right)}
$$

If $V_{H}-V_{L}<<V_{L}-\left(\frac{R_{p}}{R_{f}} V_{o}+\frac{R_{p}}{R_{L}} V_{i L}\right)$ Equation

(9) can be

approximated as follows:

$$
T_{O F F} \approx C R_{p} \frac{V_{H}-V_{L}}{V_{L}-\left(\frac{R_{p}}{R_{f}} V_{o}+\frac{R_{p}}{R_{L}} V_{i L}\right)}
$$

Combining (4) and (9) obtains the duty ratio $D=T_{O N} /\left(T_{O N}+\right.$ $\left.T_{\text {OFF }}\right)$ as follows:

$$
\left.D=\frac{\ln \frac{\frac{R_{p}}{R} V_{O H}+\frac{R_{p}}{R_{f}} V_{o}+\frac{R_{p}}{R_{L}} V_{i L}-V_{L}}{\frac{R_{p}}{R} V_{O H}+\frac{R_{p}}{R_{f}} V_{i L}-V_{H}}}{\ln \left(\frac{\frac{R_{p}}{R} V_{O H}+\frac{R_{p}}{R_{f}} V_{o}+\frac{R_{p}}{R_{L}} V_{i L}-V_{L}}{R_{O H}+\frac{R_{p}}{R_{f}} V_{o}+\frac{R_{p}}{R_{L}} V_{i L}-V_{H}} \times \frac{R_{p}}{R_{f}} V_{o}+\frac{R_{p}}{R_{L}} V_{i L}\right)}\right)
$$

Frequency $f \mathrm{~s}$ is as follows:

$$
f_{S}=\frac{1}{C R_{p}} \ln \left(\frac{\left(\frac{R_{p}}{R} V_{O H}+\frac{R_{p}}{R_{f}} V_{o}+\frac{R_{p}}{R_{L}} V_{i L}-V_{H}\right)\left(V_{L}-\frac{R_{p}}{R_{f}} V_{o}-\frac{R_{p}}{R_{L}} V_{i L}\right)}{\left(\frac{R_{p}}{R} V_{O H}+\frac{R_{p}}{R_{f}} V_{o}+\frac{R_{p}}{R_{L}} V_{i L}-V_{L}\right)\left(V_{H}-\frac{R_{p}}{R_{f}} V_{o}-\frac{R_{p}}{R_{L}} V_{i L}\right)}\right)
$$

Combining (5), (10), and $D=T_{\mathrm{ON}} /\left(T_{\mathrm{ON}}+T_{\mathrm{OFF}}\right)$ obtains the output voltage as follows:

$$
\begin{gathered}
V_{o}=\frac{V_{L} V_{i}}{\left(\frac{R_{p}}{R_{f}}+\frac{R_{p} K_{L}}{R_{L} R_{o}}\right) V_{i}+\frac{R_{p}}{R}+V_{L}-V_{H}} \\
V_{L}=\frac{R_{2}}{R_{1}+R_{2}} V_{\text {ref }}+\frac{R_{1}}{R_{1}+R_{2}} V_{O L}
\end{gathered}
$$

where

$$
\begin{aligned}
V_{H} & =\frac{R_{2}}{R_{1}+R_{2}} V_{r e f}+\frac{R_{1}}{R_{1}+R_{2}} V_{O H} \\
V_{i L} & =K_{L} i_{L}
\end{aligned}
$$

\section{B. Dynamic Analysis}

The small-signal circuit model is obtained by applying PWM switching modeling techniques. This application helps to further analyze the dynamic characteristics of the buck

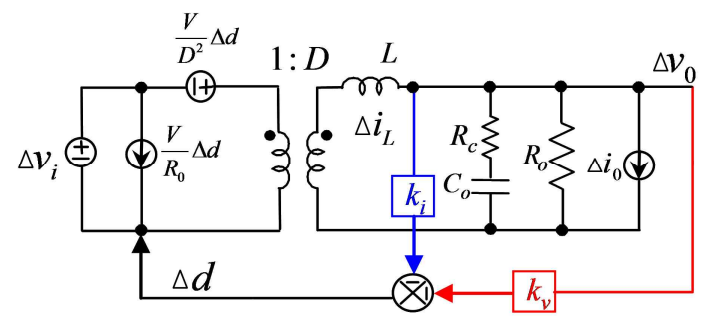

Fig. 3. Small signal equivalent circuit.

converter circuit. Fig. 3 shows the small-signal equivalent circuit of a buck converter with the proposed control strategy. In Fig. 3, $k_{i}$ is the gain of the inductor current feedback circuit, and $k_{v}$ is the gain of the output voltage feedback circuit. $R_{c}$ is the series-equivalent resistance of capacitor $C$. Based on Figure 3 , the small-signal transfer functions can be obtained.

$$
\begin{gathered}
G_{v d}(s)=\frac{\Delta v_{o}}{\Delta d}=V_{i} \frac{s R_{C} C_{o}+1}{s^{2} L C_{o}\left(1+\frac{R_{C}}{R_{o}}\right)+s\left(\frac{L}{R_{o}}+R_{C} C_{o}\right)+1} \\
G_{v v}(s)=\frac{\Delta v_{o}}{\Delta v_{i}}=D \frac{s R_{C} C_{o}+1}{s^{2} L C_{o}\left(1+\frac{R_{C}}{R_{o}}\right)+s\left(\frac{L}{R_{o}}+R_{C} C_{o}\right)+1} \\
Z_{\text {out }}(s)=\frac{\Delta v_{o}}{-\Delta i_{o}}=\frac{s L\left(s R_{C} C_{o}+1\right)}{s^{2} L C_{o}\left(1+\frac{R_{C}}{R_{o}}\right)+s\left(\frac{L}{R_{o}}+R_{C} C_{o}\right)+1} \\
G_{i v}(s)=\frac{\Delta i_{L}}{\Delta d}=\frac{V_{i}}{R_{o}} \frac{s C_{o}\left(R_{o}+R_{C}\right)+1}{s^{2} L C_{o}\left(1+\frac{R_{C}}{R_{o}}\right)+s\left(\frac{L}{R_{o}}+R_{C} C_{o}\right)+1} \\
G_{i i}(s)=\frac{D}{R_{o}} \frac{s C_{o}\left(R_{o}+R_{C}\right)+1}{\Delta i_{o}}=\frac{s^{2} L C_{o}\left(1+\frac{R_{C}}{R_{o}}\right)+s\left(\frac{L}{R_{o}}+R_{C} C_{o}\right)+1}{s^{2} L C_{o}\left(1+\frac{R_{C}}{R_{o}}\right)+s\left(\frac{L}{R_{o}}+R_{C} C_{o}\right)+1}
\end{gathered}
$$

Combining (5) and (10) obtains the duty ratio $D=T_{O N} /\left(T_{O N}+\right.$ $T_{\text {OFF }}$ ) approximately as follows:

$$
d=\frac{V_{L}-\left(\frac{R_{p}}{R_{f}} v_{o}+\frac{R_{p}}{R_{L}} k_{L} i_{L}\right)}{V_{L}-V_{H}+\frac{R_{p}}{R} V_{O H}}
$$

The small signal disturbance of (20) can be represented as follows:

$$
\begin{aligned}
& d=d=D+\Delta d \\
& v_{o}=V_{o}+\Delta v_{o} \\
& i_{L}=I_{L}+\Delta i_{L}
\end{aligned}
$$

From (20) and (21), the following formula can be obtained:

$$
D+\Delta d=\frac{V_{L}-\left[\frac{R_{p}}{R_{f}}\left(V_{o}+\Delta v_{o}\right)+\frac{R_{p}}{R_{L}} k_{L}\left(I_{L}+\Delta i_{L}\right)\right]}{V_{L}-V_{H}+\frac{R_{p}}{R} V_{O H}}
$$

Combining (20) and (22) obtains the gain of the output voltage feedback and inductor current feedback circuit as 
follows:

$$
\begin{gathered}
k_{v}=\frac{\Delta d}{\Delta v_{o}}=\frac{\frac{R_{p}}{R_{f}}}{V_{L}-V_{H}+\frac{R_{p}}{R} V_{O H}} \\
k_{i}=\frac{\Delta d}{\Delta i_{L}}=\frac{\frac{R_{p}}{R_{L}} k_{L}}{V_{L}-V_{H}+\frac{R_{p}}{R} V_{O H}}
\end{gathered}
$$

Fig. 4 shows a control block diagram of the circuit proposed in this paper. In Fig. 4, the loop gain transfer function of the proposed controller is expressed as follows:

$$
\begin{gathered}
T(s)=k_{i} G_{i d}(s)+k_{v} G_{v d}(s) \\
=\frac{s\left[\frac{k_{i} V_{i}}{R_{o}} C_{o}\left(R_{o}+R_{C}\right)+k_{v} V_{i} R_{C} C_{o}\right]+\frac{k_{i} V_{i}}{R_{o}}+k_{v} V_{i}}{s^{2} L C_{o}\left(1+\frac{R_{C}}{R_{o}}\right)+s\left(\frac{L}{R_{o}}+R_{C} C_{o}\right)+1}
\end{gathered}
$$

The closed-loop transfer function can be obtained according to Mason's rule.

"Control-to-Output" is as follows:

$$
\begin{aligned}
& G_{v d-c}(s)=\left.\frac{\Delta v_{o}}{\Delta d}\right|_{\substack{\Delta v_{i}(s)=0 \\
\Delta i_{o}(s)=0}}=\frac{G_{v d}}{1+k_{i} G_{i d}+k_{v} G_{v d}} \\
& =\frac{V_{i}\left(s R_{C} C_{o}+1\right)}{s^{2} a_{2}+s a_{1}+a_{0}} \\
& \text { where } \begin{aligned}
a_{2}= & L C_{o}\left(1+\frac{R_{C}}{R_{o}}\right) \\
a_{1} & =\frac{k_{i} V_{i}}{R_{o}} C_{o}\left(R_{o}+R_{C}\right)+R_{C} C_{o}\left(k_{v} V_{i}+1\right)+\frac{L}{R_{o}} \\
a_{0}= & \frac{k_{i} V_{i}}{R_{o}}+k_{v} V_{i}+1
\end{aligned}
\end{aligned}
$$

"Input voltage susceptibility" is as follows:

$$
G_{v v-c}(s)=\left.\frac{\Delta v_{o}}{\Delta v_{i}}\right|_{\Delta i_{o}(s)=0}=\frac{G_{v v}-k_{i}\left(G_{v v} G_{i d}-G_{i v} G_{v d}\right)}{1+k_{i} G_{i d}+k_{v} G_{v d}}
$$

If $G_{v v} G_{d i}-G_{v i} G_{v d}=0$, Equation (26) can be written as follows:

$$
\begin{aligned}
G_{v v-c}(s)=\left.\frac{\Delta v_{o}}{\Delta v_{i}}\right|_{\Delta i_{o}(s)=0} & =\frac{G_{v v}}{1+k_{i} G_{i d}+k_{v} G_{v d}} \\
& =\frac{D\left(s R_{C} C_{o}+1\right)}{s^{2} a_{2}+s a_{1}+a_{0}}
\end{aligned}
$$

"Output impedance" is as follows:

$$
\begin{aligned}
Z_{\text {out }-c}(s)=\left.\frac{\Delta v_{o}}{\Delta i_{o}}\right|_{\Delta v_{i}(s)=0} & =\frac{Z_{\text {out }}}{1+k_{i} G_{i d}+k_{v} G_{v d}} \\
& =\frac{s L\left(s R_{C} C_{o}+1\right)}{s^{2} a_{2}+s a_{1}+a_{0}}
\end{aligned}
$$

Fig. 5 shows the results of the frequency response of the loop gain of output voltage feedback control transfer function. The feedback resistor $R_{f}$ is taken as a parameter. The frequency response of the gain and phase shows that the control loop is steady and possesses good phase margin at

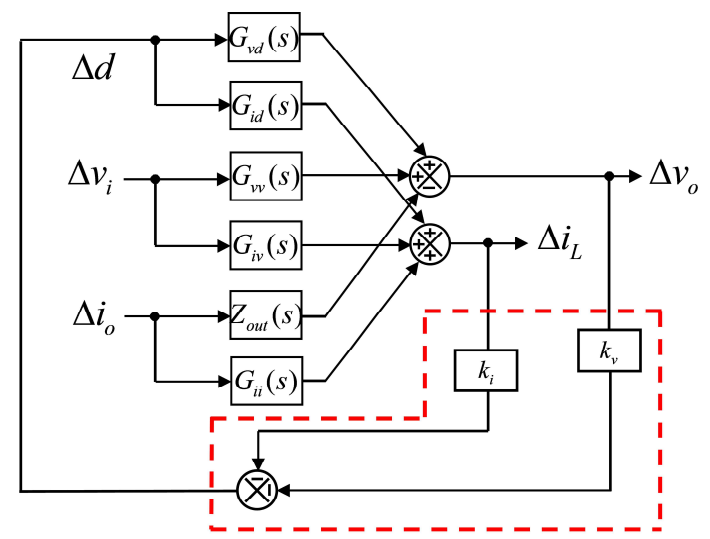

Fig. 4. Control block diagram of the buck converter employing the proposed control scheme.

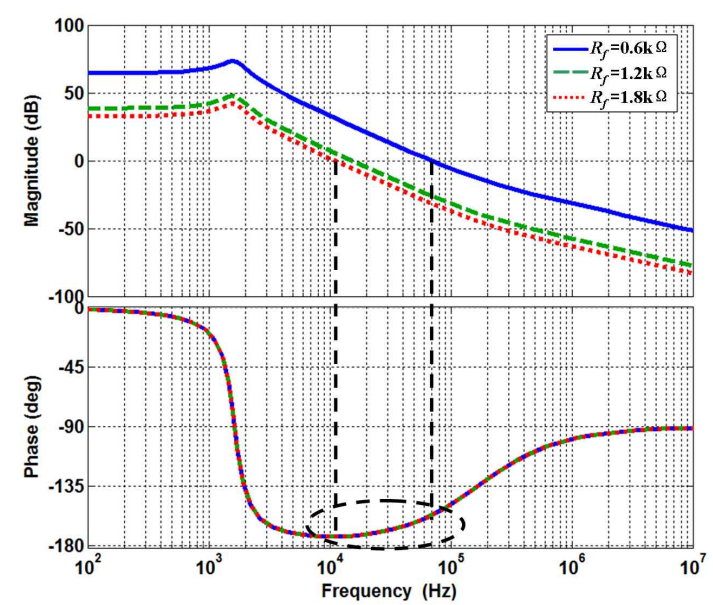

Fig. 5. Frequency response of the loop gain of output voltage feedback control with different $R_{f}$.

different $R_{f}$. The smaller $R_{f}$ has higher gain in all frequencies and better phase margin. In addition, Fig. 6 shows the results of the frequency response of the loop gain of the inductor current feedback control transfer function, which takes the feedback resistor $R_{L}$ as a parameter. The control loop is also seen as steady. The smaller $R_{L}$ has higher gain in all frequencies, but the phase margin is kept unchanged.

The above analysis shows that taking $R_{f}, R_{L}$ between the gain of open loop transfer function and phase margin is a trade-off. Results show that good performance of proposed controller was achieved with $R_{f}(=0.6 \mathrm{k} \Omega)$ and $R_{L}(=40 \mathrm{k} \Omega)$.

The loop gain transfer function $T(\mathrm{~s})$ of the proposed controller is shown in Fig. 7. The frequency response of loop gain for the buck converter with feedback $T(\mathrm{~s})$ and without any feedback $G_{v d}(\mathrm{~s})$ is compared. The figure shows that feedback control increases the loop DC gain from $14 \mathrm{~dB}$ to $64.6 \mathrm{~dB}$, which also has a larger cut-off frequency of $72.9 \mathrm{kHZ}$. The phase margin was increased to $35^{\circ}$ and $T(\mathrm{~s})$ has $40 \mathrm{~dB}$ attenuation in middle-high frequency. This margin is effective in high-frequency interference mitigation. Hence, both good stability and wide bandwidth are easily achieved if the feedback loop is added. Therefore, the dynamic characteristic is verified. 


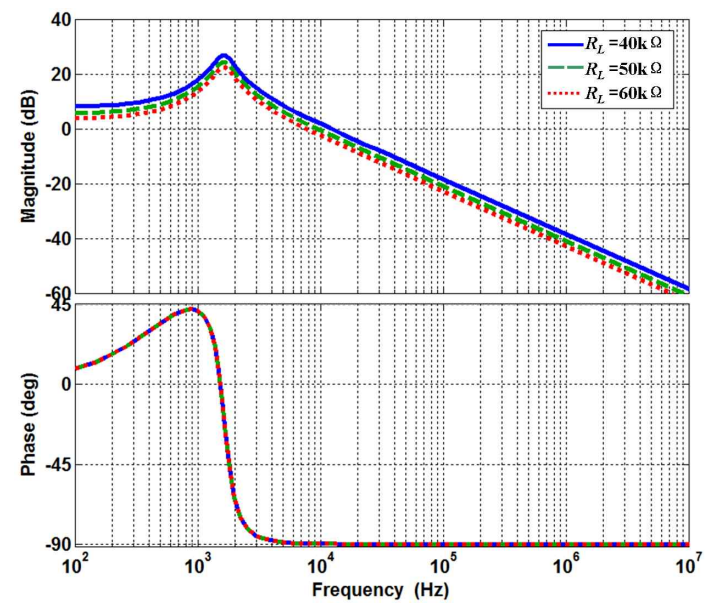

Fig. 6. Frequency response of the loop gain of inductor current feedback control with different $R_{L}$.

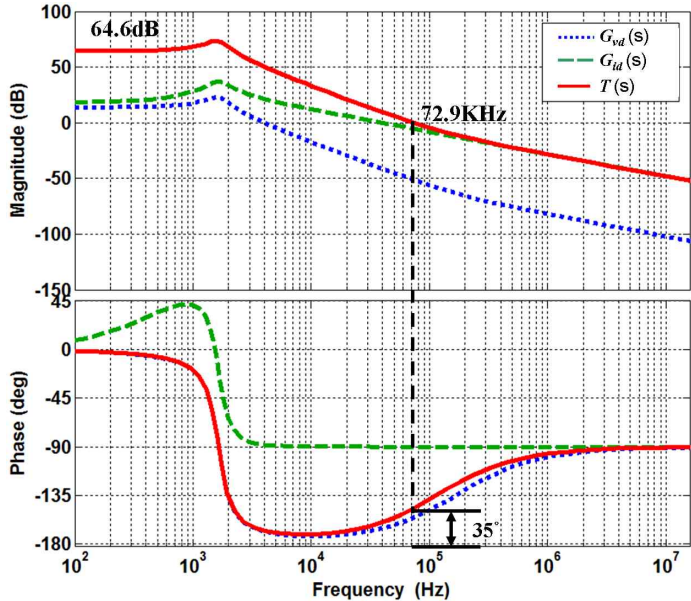

Fig. 7. Frequency response of the loop gain $T(\mathrm{~s})$.

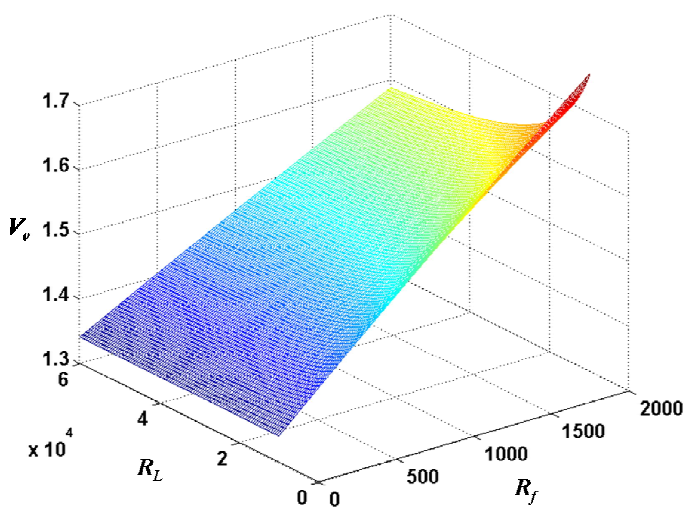

Fig. 8. Effect of $R_{L}$ and $R_{f}$ to $V o$.

Fig. 8 describes the relationship of inductor current feedback resistor $R_{L}$ output voltage feedback resistor $R_{f}$ and output voltage $V_{o}$. This figure shows that feedback control parameters must be selected in a certain range to stabilize the output voltage.

Fig. 9(a) shows a Nyquist diagram of the transfer function. Point $(-1,0 i)$ is not surrounded by the Nyquist plot. In addition,

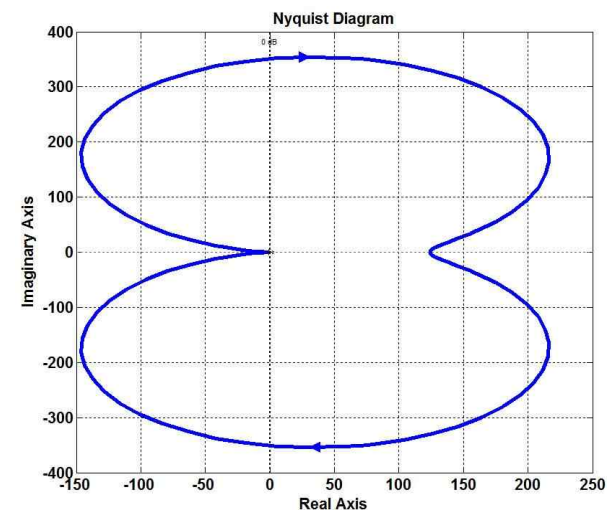

(a)

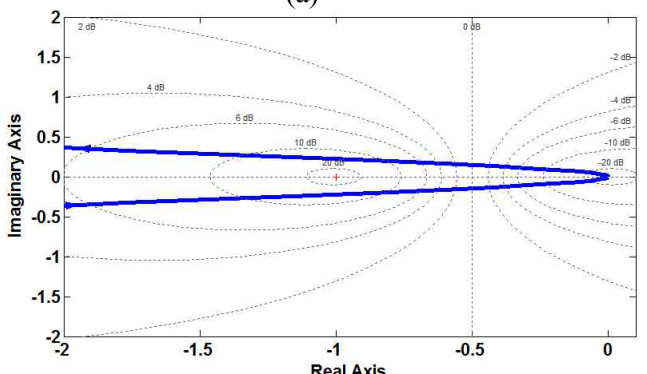

(b)

Fig. 9. (a) Nyquist diagram of loop gain transfer function. (b) Amplification region at point $(-1,0 \mathrm{i})$

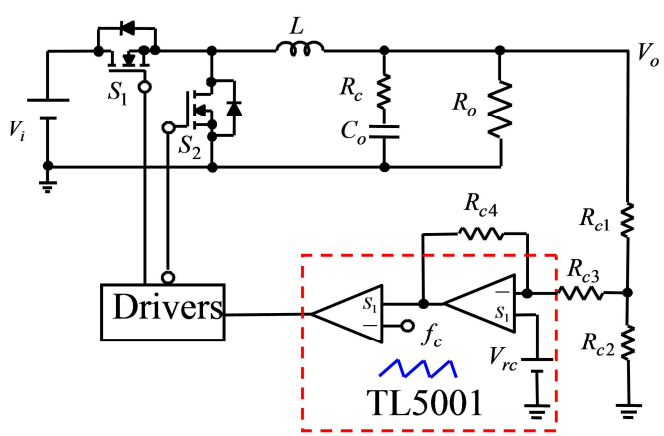

Fig. 10. Traditional voltage-mode controlled buck converter.

no pole points of the open transfer function in the right half plane are found. The stability of the buck converter control system is obtained in terms of the Nyquist stability criterion. Fig. 9(b) shows the part of the amplification region at point $(-1,0 i)$ of the Nyquist plot. Point $(-1,0 i)$ is not be surrounded or passed through by the Nyquist plot.

\section{SiMULATION AND EXPERIMENTAL RESULTS}

A simulation model based on Fig. 1 was built in PSIM to verify the proposed control strategy, and a prototype was designed. The circuit parameters are shown in Table I. The conventional PWM controller is a TL5001 PWM controller. The regulator uses the PI compensation network, as shown in Fig. 10.

Fig. 11 shows the relation between the output current and the output voltage. The variations of the output voltage are 
TABLE I

Design Parameters of the Proposed Converter

\begin{tabular}{c|c}
\hline Parameters & Values \\
\hline DC Source Voltage $V_{i}$ & $5 \mathrm{~V}$ \\
\hline Output Voltage $V_{o}$ & $1.5 \mathrm{~V}$ \\
\hline Resistance $R_{I}$ & $560 \Omega$ \\
\hline Resistance $R_{2}$ & $10 \mathrm{k} \Omega$ \\
\hline Filter Inductance $L$ & $20 \mathrm{uH}$ \\
\hline Comparator Resistance $R$ & $10 \mathrm{k} \Omega$ \\
\hline Capacitance $C$ & $2200 \mathrm{pF}$ \\
\hline Filter Capacitance $C_{o}$ & $470 \mathrm{uF}$ \\
\hline ESR $R_{c}$ & $2 \mathrm{~m} \Omega$ \\
\hline Feedback Resistance $R_{f}$ & $0.6 \mathrm{k} \Omega$ \\
\hline Feedback Resistance $R_{L}$ & $40 \mathrm{k} \Omega$ \\
\hline Proportion Coefficient $k_{L}$ & 0.06
\end{tabular}

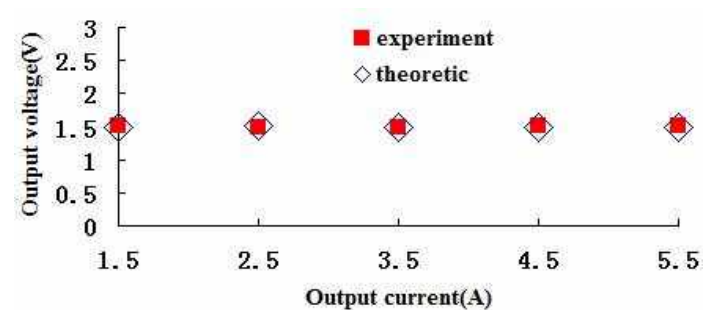

Fig. 11. Relation of the output current and output voltage.

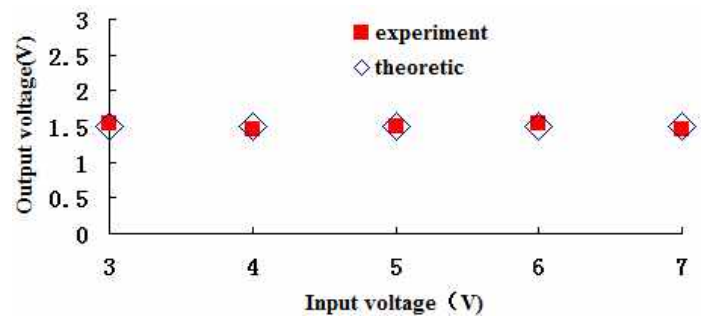

Fig. 12. Relation of the input voltage and output voltage.

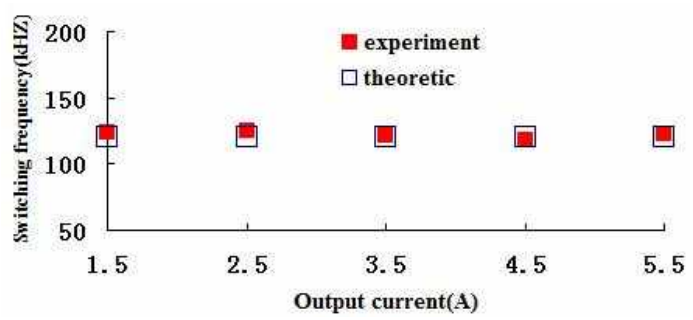

Fig. 13. Relation of the output current and switching frequency.

extremely small, as seen in the figure. The simulation values of the output voltage are in good agreement with the experimental values. Fig. 12 shows the relation between the input voltage and output voltage. The variation of the output voltage is also extremely small despite significant variation in the input voltage. No steady-state error is observed in the output voltage when changes of the input voltage and load current occur. The same observation is found even when the controller does not employ a high-gain operational amplifier.

Fig. 13 shows the relation between the output current and switching frequency. The figure shows that the switching
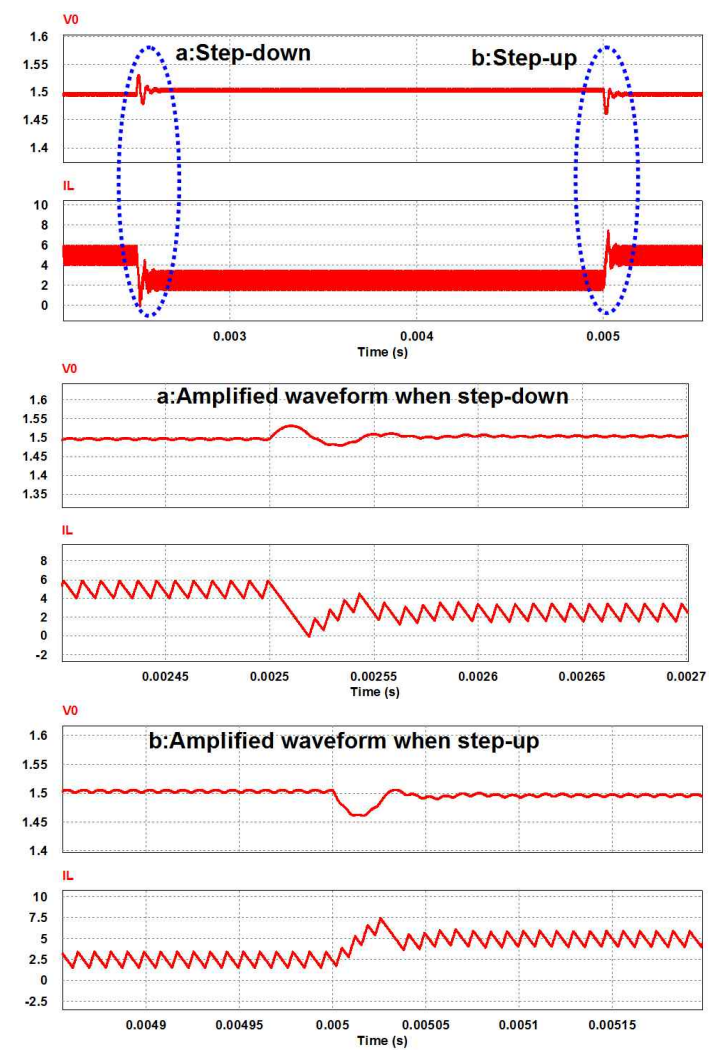

Fig. 14. Waveforms of output voltage and inductor current during load transients.

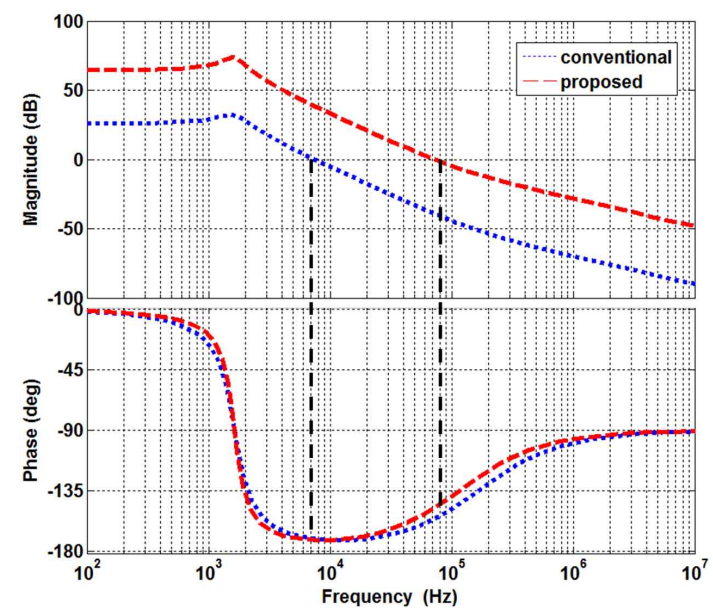

Fig. 15. Bode diagram of loop gain function.

frequency remained at $120 \mathrm{kHz}$ when the load current changed. Moreover, the drawback of variable frequency was solved compared with some control technologies.

Fig. 14 shows the output voltage and inductor current waveforms during load transients. The load current initially decreased from $5 \mathrm{~A}$ to $2 \mathrm{~A}$. The excess inductor current decreased slowly with a slope proportional to $V_{o}$. Operations were in the opposite direction when the load current increased from $2 \mathrm{~A}$ to $5 \mathrm{~A}$. In addition, the output voltage drops with magnitude proportion and inductor current increased quickly with a slope proportional to $V_{\mathrm{i}}-V_{\mathrm{o}}$. Therefore, $V_{\mathrm{o}}$ quickly recovered. Moreover, the regulator was consistently stable 


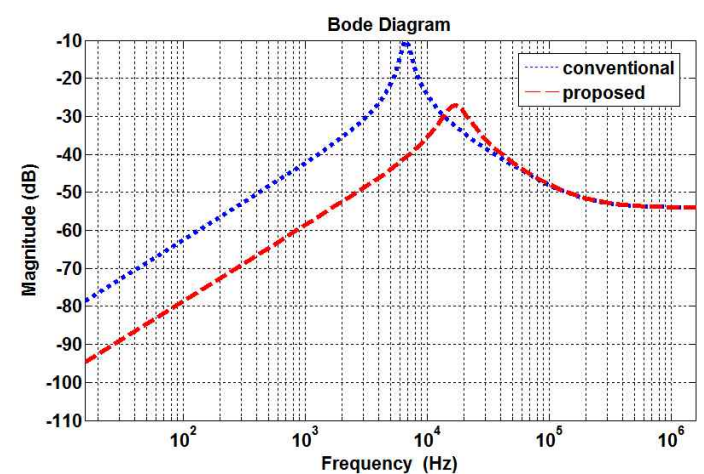

Fig. 16. Bode diagram of output impedance.

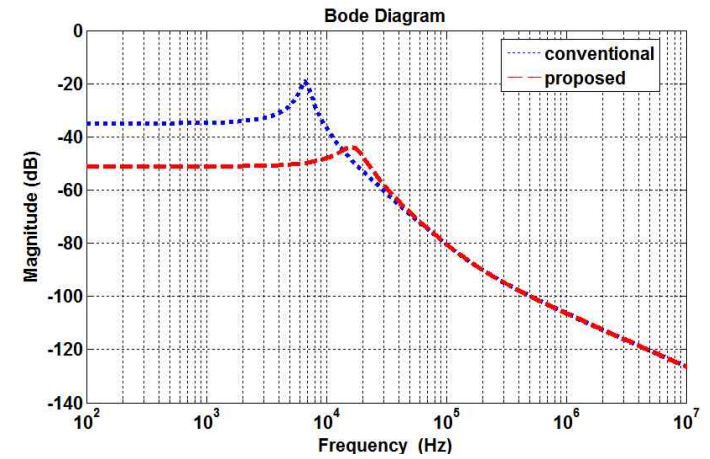

Fig. 17. Bode diagram of input-to-output function.

during the load transients.

Below is a comparative analysis of conventional and proposed controllers. Fig. 15 shows the loop gain transfer function of the conventional and the proposed controllers. The proposed controller has higher gain in all frequency ranges, a higher cut-off frequency, and a higher phase margin than the conventional controller. This controller is simple to use in outer circuit design, which results in high closed-loop gain and high closed-loop bandwidth. Therefore, the proposed controller has a higher sensitivity to control signal and faster response than the conventional controller.

Fig. 16 shows the "output impedance" transfer function of the two. The output impedance of the circuit is mainly decided by the parasitic resistance of the output filter capacitor at high frequency ranges. Hence, both controllers have the same output impedance at high frequency ranges. In addition, the proposed controller has lower output impedance at medium and low frequency ranges. Therefore, the output voltage is less affected by changes in load current compared with the conventional controller. Consequently, better dynamic load performance is achieved.

Fig. 17 shows the "input voltage susceptibility" transfer function of the two. The proposed controller has lower gain than the conventional controller at low and medium frequency ranges. Hence, the proposed controller has better anti-input voltage disturbance capability.

Figs. 18(a) and 18(b) show the simulated and experimental responses of the proposed and conventional controllers that

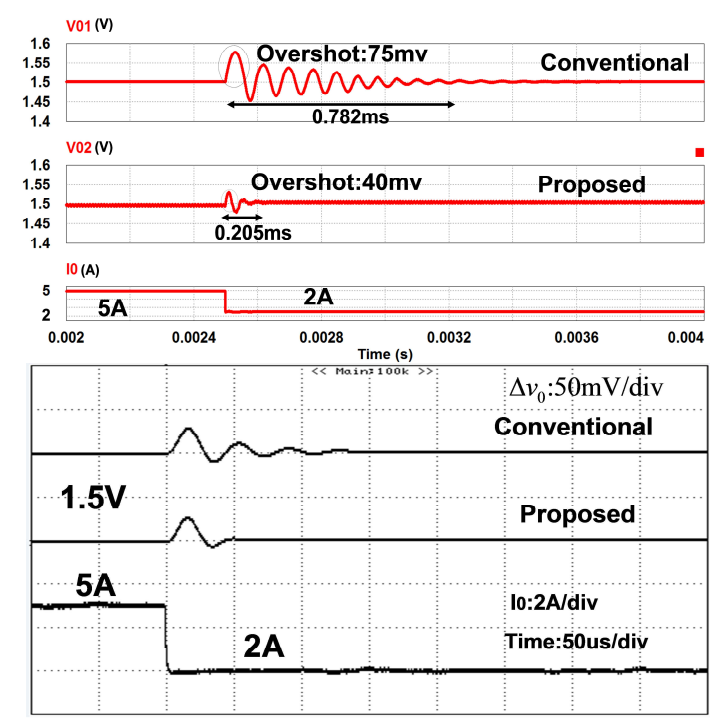

(a)

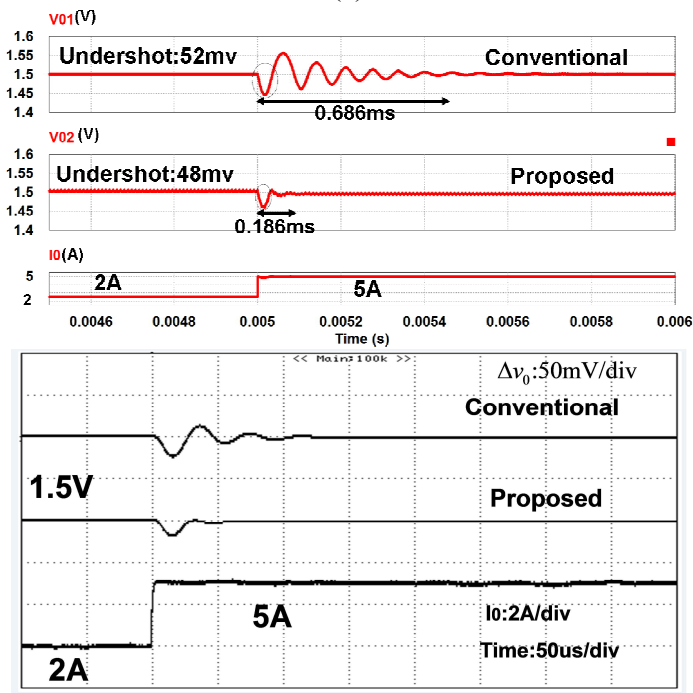

(b)

Fig. 18. (a) Simulated and experimental response to a $5 \mathrm{~A}$ to $2 \mathrm{~A}$ load current step change. (b) Simulated and experimental response to a $2 \mathrm{~A}$ to $5 \mathrm{~A}$ load current step change.

undergo load current step changes of $5 \mathrm{~A}$ to $2 \mathrm{~A}$ and $2 \mathrm{~A}$ to $5 \mathrm{~A}$, respectively. The proposed controller not only has a short response time, but also a small overshoot and undershoot. Hence, this controller has better dynamic response characteristics than the conventional controller.

\section{CONCLUSIONS}

This paper proposed and analyzed a novel hysteresis PWM control strategy applied to a buck switching converter. The proposed control strategy based on ampere-second balance characteristics of the modulate capacitor uses the output feedback signal for capacitor charging and discharging to generate modulation voltage $V_{f}$. This technique is simple and solves the compensation problem of the error amplifier in conventional voltage PWM control. This strategy also achieves 
faster transient response and quasi-switching frequency to meet the challenges of power supply requirements for fast dynamic load changes. Finally, the steady-state and dynamic operation of the proposed control method are analyzed and verified by simulation and experimental results.

\section{ACKNOWLEDGMENT}

The authors would like to acknowledge the financial support of the Shanghai Talent Development Fund (Grant No. 2012024), the Innovation Program of Shanghai Municipal Education Commission (Grant No. 13ZZ132), and Shanghai Green Energy Grid Connected Technology Engineering Research Center (Grant No. 13DZ2251900).

\section{REFERENCES}

[1] H. Y. Cha, R. J. Ding, Q. S. Tang, and F. Z. Peng, "Design and development of high power dc-dc converter for metro vehicle system," IEEE Trans. Ind. Appl., Vol. 44, No. 6, pp. 1795-1804, Dec. 2008.

[2] S. Kapat and P. T. Krein, "Improved time optimal control of a buck converter based on capacitor current," IEEE Trans. Power Electron., Vol. 27, No. 3, pp. 1444-1454, Mar. 2012.

[3] R. Mohsen, L. W. Zhou, and M. Nasser, "Improvement of one-cycle controller response with a current mode controller," Journal of Power Electronics, Vol. 10, No. 1, pp. 461-467, Jan. 2010.

[4] I.-D. Kim, J.-Y. Kim, E.-C. Nho, and H.-G. Kim, "Analysis and design of a soft-switched pwm sepic dc-dc converter," Journal of Power Electronics, Vol. 10, No. 5, pp. 461-467,Sep. 2010.

[5] W. R. Liou, M. L. Yeh, and Y. L. Kuo, "A high efficiency dual-mode buck converter integrated circuit for portable applications," IEEE Trans. Power Electron, Vol. 23, No. 2, pp. 667-677, Mar. 2008.

[6] H. H. Huang, C. L. Chen, and K. H. Chen, “Adaptive window control (AWC) technique for hysteresis DC-DC buck converters with improved light and heavy load performance," IEEE Trans. Power Electron., Vol. 24, No. 6, pp. 1607-1617, Jun. 2009.

[7] X. H. Wu and X. B. Wu. "Adaptive hysteresis window control (AHWC) technique for hysteresis DC-DC buck converter with constant switching frequency," Power and Energy Engineering Conference, 2010 Asia-Pacific, pp. $1-4,2010$.

[8] S. Chattopadhyay and S. Das "A digital current-mode control technique for DC-DC converters," IEEE Trans. Power Electron., Vol. 21, No. 6, pp. 1718-1726, Nov. 2006.

[9] C. H. Chang and R. C. Chang, "A novel current sensing circuit for a current-mode control CMOS DC-DC buck converter," 2005 IEEE VLSI-TSA International Symposium on VLSI Design, Automation and Test, (VLSI-TSA-DAT) , pp. 120-123, 2005.

[10] Y. F. Liu, E. Meyer, and X. Liu, "Recent developments in digital control strategies for DC/DC switching power converters," IEEE Trans. Power Electron., Vol. 24, No. 11, pp. 2567-2577, Nov. 2009.

[11] C. A. Yeh and Y. S. Lai, "Digital pulsewidth modulation technique for a synchronous buck DC/DC converter to reduce switching frequency, "IEEE Trans. Ind. Electron., Vol. 59, No. 1, pp. 550-561, Jan. 2012.

[12] S. H. Kang, D. Maksimovic, and I. Cohen, "Efficiency optimization in digitally controlled flyback DC-DC converters over wide ranges of operating conditions," IEEE Trans. Power Electron, Vol. 27, No. 8, pp. 3734-3748, Aug. 2012.

[13] M. Lopez, L.G. de Vicuna, M. Castilla, P. Gaya, and O. Lopez, "Current distribution control design for paralleled DC/DC converters using sliding-mode control, " IEEE Trans. Ind. Electron., Vol. 51, No. 2, pp. 419-428, Apr. 2004.

[14] S. Guo, X. Lin-Shi, B. Allard, Y.-X. Gao, and Y. Ruan, "Digital sliding-mode controller for high-frequency dc/dc SMPS," IEEE Trans. Power Electron., Vol. 25, No. 5, pp. 1120-1123, May 2010.

[15] M. Hoyerby and M. A. E. Andersen, "Accurate sliding-mode control system modeling for buck converters," 2007 European Conference on Power Electronics and Applications, pp. 1-10, 2007.

[16] S. C. Huerta, P. Alou, J. A. Oliver, O. García, J.A. Cobos, and A. M. Abou-Alfotouh, "Nonlinear control for DC-DC converters based on hysteresis of the $C_{\text {OUT }}$ current with a frequency loop to operate at constant frequency," IEEE Trans. Ind. Electron., Vol. 58, No. 3, pp. 1036-1043, Mar. 2011.

[17] S. C. Huerta, P. Alou, O. Garcia, J. A. Oliver, R. Prieto, and J. Cobos, "Hysteretic mixed-signal controller for high-frequency DC-DC converters operating at constant switching frequency," IEEE Trans. Power Electron., Vol. 27, No. 6, pp. 2690-2696, Jun. 2012.

[18] S. Poulsen and M. A. E. Andersen, "Hysteresis controller with constant switching frequency," IEEE Trans. Consum. Electron., Vol. 51, No. 2, pp. 688-693, May. 2005.

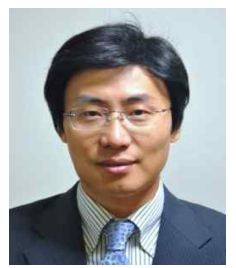

Jin-Bin Zhao (M'06) was born in China in 1972. He received his M.S. and Ph.D. in Electrical Engineering from Oita University, Oita, Japan, in 2002 and 2005, respectively. $\mathrm{He}$ worked as a researcher at the R\&D Headquarters of Origin Electric Co., Ltd, Japan, from 2005 to 2011 . He is currently a professor at the Shanghai University of Electric Power, Shanghai, China. His current research interests include control of power converters, soft-switching power converters, inverters, distributed power systems, power-factor correction, and electric drive systems. He currently holds three U.S. patents, ten Japanese patents, and five Chinese patents. He has published 60 technical papers in journals and conference proceedings. Dr. Zhao is a member of the Institute of Electrical Engineers of Japan and the Institute of Electronics Information and Communication Engineers of Japan as well as a senior member of the China Power Supply Society.

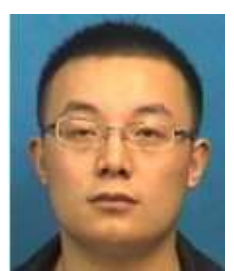

Jian-Feng Dai was born in China in 1989. $\mathrm{He}$ will receive his M.S. in Electrical Engineering from the Shanghai University of Electric Power, Shanghai, China, in 2015. His current research interests include modeling and control of DC-DC converter and inverter. 


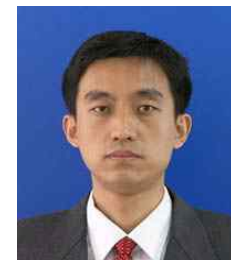

Ke-Qing Qu was born in China in 1970. He received his $\mathrm{Ph} . \mathrm{D}$. in Electrical Engineering from Shanghai University, Shanghai, China, in 2004. He is currently an associate professor at the Shanghai University of Electric Power, Shanghai, China. He is also a master instructor. He studied in Germany as a visiting scholar with full funding by the national foundation from 2009 to 2010. His current research interests include power electronic conversion and new energy generation and its application to power systems. He holds one Chinese patent, one monograph, and more than 30 academic theses, 12 of which were included in the international Engineering Index.

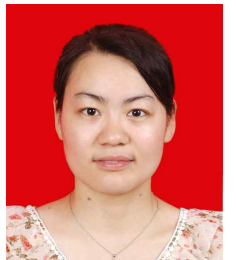

Fen Li received her BS and Ph.D. degrees in Electrical Engineering from Huazhong University of Science and Technology, Wuhan, P.R. China, in 2005 and 2010, respectively. She has been an engineer in Hubei Meteorological Bureau, Wuhan, P.R. China, since 2010. Currently, she is a teacher at the Shanghai University of Electric Power, Shanghai, P.R. China. Her research interests are high power factor converters (power factor correction and PWM rectifier), grid-connected control of renewable energy power generation, solar resource evaluation and forecast, relationship of photovoltaic power and meteorological factors, and PV power prediction. To date, she has published 15 technical papers in journal and conference proceedings. 